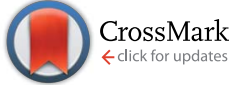

Cite this: J. Mater. Chem. B, 2014, 2 , 5799

Received 7th May 2014

Accepted 24th June 2014

DOI: $10.1039 / c 4 t b 00733 f$

www.rsc.org/MaterialsB

\section{Addressing the optimal silver content in bioactive glass systems in terms of BSA adsorption}

\author{
Klára Magyari, ${ }^{\text {a }}$ Cristina Gruian, ${ }^{\text {ab }}$ Béla Varga, ${ }^{\mathrm{c}}$ Raluca Ciceo-Lucacel, ${ }^{a}$ \\ Teodora Radu, ${ }^{a}$ Heinz-Jürgen Steinhoff, ${ }^{b}$ György Váró, ${ }^{c}$ Viorica Simon ${ }^{a}$ \\ and Lucian Baia*a
}

Bioactive glasses doped with silver are aimed to minimize the risk of microbial contamination; therefore, the influence of silver on the bioactive properties is intensely investigated. However, information related to the role played by silver, when added to the bioactive glass composition, on biocompatibility properties is scarce. This aspect is essential as long as the silver content can influence blood protein adsorption onto the surface of the glass, thus affecting the material's biocompatibility. Therefore, from the perspective of the biocompatibility standpoint, the finding of an optimal silver content in a bioactive glass is an extremely important issue. In this study, silver-doped bioactive glasses were prepared by a melt-derived technique, which eliminates the pores' influence in the protein adsorption process. The obtained glasses were characterized by X-ray diffraction, UV-vis, X-ray photoelectron (XPS) and Fourier transform infrared (FT-IR) spectroscopy; afterwards, they were investigated in terms of protein adsorption. Both UV-vis and XPS spectroscopy revealed the presence of $\mathrm{Ag}^{+}$ions in all silver containing samples. By increasing the silver content, metallic $\mathrm{Ag}^{0}$ appears, the highest amount being observed for the sample with $1 \mathrm{~mol} \%$ $\mathrm{AgO}_{2}$. Electron paramagnetic resonance measurements evidenced that the amount of spin-labeled serum albumin attached to the surface increases with the silver content. The results obtained by analyzing the information derived from atomic force microscopy and FT-IR measurements indicate that the occurrence of metallic $\mathrm{Ag}^{\mathrm{O}}$ in the samples' structure influences the secondary structure of the adsorbed protein. Based on the results derived from the protein response upon interaction with the investigated glass calcium-phosphate based system, the optimal silver oxide concentration was determined for which the secondary structure of the adsorbed protein is similar with that of the free one. This concentration was found to be $0.5 \mathrm{~mol} \%$.

\section{Introduction}

It is well known that the presence of silver oxide in bioactive glass composition reduces the risk of microbial contamination through leakage of silver ions, ${ }^{\mathbf{1 , 2}}$ due to their oligodynamic activity. ${ }^{3,4}$ Phosphate-based glasses in the $\mathrm{P}_{2} \mathrm{O}_{5}-\mathrm{CaO}-\mathrm{Na}_{2} \mathrm{O}$ system have a high level of interest as bone filling material and for scaffold fabrication in bone tissue engineering due to their high solubility and chemical similarity with the inorganic phase of human bone. ${ }^{5}$ Ahmed et al. ${ }^{6}$ demonstrated that an incorporation of up to $2 \mathrm{~mol} \% \mathrm{Ag}_{2} \mathrm{O}$ into ternary system $\mathrm{P}_{2} \mathrm{O}_{5}-\mathrm{CaO}-$ $\mathrm{Na}_{2} \mathrm{O}$ confirms the antibacterial activity. Nevertheless, in the body fluid, the release of silver ions is obstructed by the selfassembling of an apatite layer on the bioactive glass surface. ${ }^{7}$

${ }^{a}$ Babes-Bolyai University, Faculty of Physics \& Institute of Interdisciplinary Research in Bio-Nano-Sciences, 400084 Cluj-Napoca, Romania. E-mail: lucian.baia@phys. ubbcluj.ro; klara.magyari@ubbcluj.ro; Fax: +40-264-591906; Tel: +40-264-405300 ${ }^{b}$ Department of Physics, University of Osnabrück, 49069 Osnabrück, Germany

'Institute of Biophysics, Biological Research Centre of the Hungarian, Academy of Sciences, 6726 Szeged, Hungary
Another important aspect that has to be considered for bone tissue engineering type materials is their bioactivity. It was recently shown that phosphate glasses doped with $1 \mathrm{~mol} \% \mathrm{Ag}_{2} \mathrm{O}$ preserve their in vitro bioactivity. ${ }^{8}$

When biomaterials are introduced into the body, they first come into contact with blood proteins, which are spontaneously adsorbed on their surface, and then cellular attachment, proliferation and migration occurs., ${ }^{\mathbf{9 1 0}}$ Although surfaceprotein interactions are not completely elucidated, surface chemistry has been shown to play a fundamental role in protein adsorption. ${ }^{11,12}$ Several studies have shown that the conformation of proteins changes upon adsorption onto the surface of the materials, thus affecting the material biocompatibility and further cellular interactions. ${ }^{9-11,13-15}$ It is already known that bovine serum albumin (BSA) displays high binding affinity towards silver nanoparticles, which in turn trigger changes in its spatial structure. ${ }^{16-18}$ The changes in the secondary structure of BSA may thus be affected by the silver content in glass.

The role played by silver in the antibacterial ${ }^{6,19-22}$ and bioactive $e^{\mathbf{8 2 3 , 2 4}}$ behaviour of glass was intensely studied lately, 
but little work has been focused on evaluating the biocompatibility of these glasses. Consequently, this study aims to investigate the way silver content in bioactive glass influences protein adsorption, as the first event occurring upon interaction with body fluids. Furthermore, it is proposed to determine the optimal $\mathrm{Ag}_{2} \mathrm{O}$ concentration in the bioactive glass, in terms of interaction with proteins. To this end, bovine serum albumin (BSA) was considered as a model protein, since it displays high structural homology with human serum albumin. ${ }^{12}$ Serum albumin is the most abundant protein, accounting for $60-70 \%$ of the measured plasma proteins and is the first protein surrounding foreign bodies when they come in contact with blood. ${ }^{25}$ The albumin structure is predominantly helical (Fig. 1) with the remaining polypeptides occurring in turns or flexible regions between the subdomains. ${ }^{26}$ Albumin is considered to greatly reduce the acute inflammatory response to

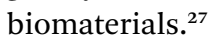

It has already been demonstrated that the sol-gel derived bioactive glass $45 \mathrm{~S} 5$ eluted more protein per unit mass than the melt-derived $45 \mathrm{~S} 5$ glass. ${ }^{28}$ To eliminate the influence of porosity on the adsorption process, in the present study, bioactive glasses were prepared by the conventional melt quenching method. Prior to protein attachment, samples of $\mathrm{P}_{2} \mathrm{O}_{5} \cdot \mathrm{CaO} \cdot \mathrm{Na}_{2} \mathrm{O}$ system doped with $\mathrm{Ag}_{2} \mathrm{O}$ were subjected to structural analysis by X-ray diffraction (XRD), UV-Vis, X-ray photoelectron spectroscopy (XPS) and Fourier transform infrared (FT-IR) spectroscopy. Conformational changes induced in the BSA structure as a consequence of interaction with the investigated samples were followed by FT-IR spectroscopy and atomic force microscopy (AFM). Spin labeling in combination with electron paramagnetic resonance (EPR) spectroscopy was employed to quantify the amount of protein attached on each

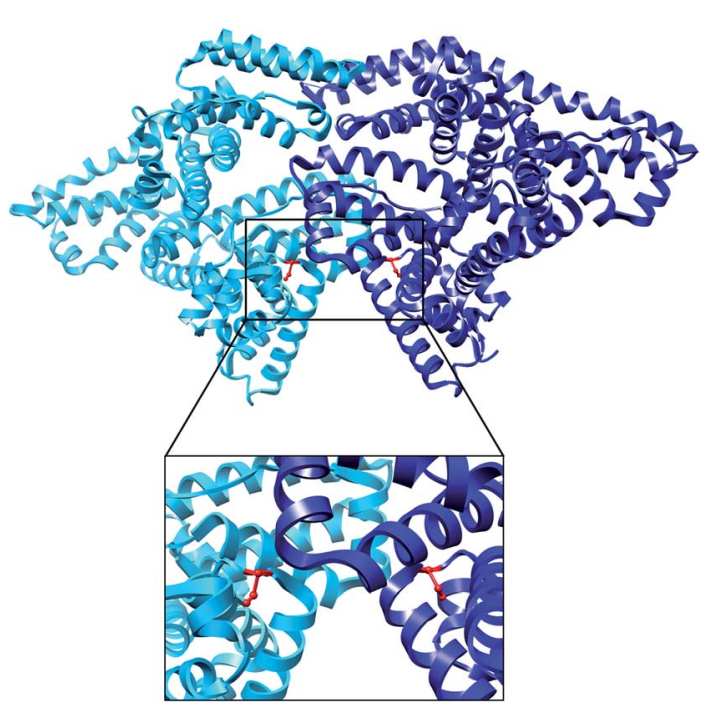

Fig. 1 The crystal structure of bovine serum albumin dimer obtained by X-ray crystallography (pdb 4F5S). The two monomers are coloured in cyan and blue, respectively. Each native cysteine at position 34 is coloured in red, and the atoms are shown as balls and sticks. The region surrounding the two Cys34 positions is enlarged in the lower part. glass sample. EPR spectroscopy provides a detailed structural, dynamic and quantitative information for biomolecules not only in solution but can also be applied to adsorbed or encapsulated spin-labeled proteins as reported recently. ${ }^{29-31}$ This method enables determining the protein amount in the overall mass of the sample, by counting the number of spins contributing to the paramagnetic signal. The EPR spectra were further used to monitor local structural changes in BSA following the adsorption process. In the present study (4-(2-iodoacetamido)2,2,6,6-tetramethyl-1-piperidinyloxy) iodoacetamide (IA) spin label was used to label the cysteine residue located at position 34 of bovine serum albumin, which contains the unique free thiol group that is not involved in a disulfide bridge (Fig. 1). BSA adsorption onto the investigated systems was explored in conditions close to its physiological environment (phosphate buffer solution at $\mathrm{pH}$ 7.4), by following the EPR signal of the paramagnetic centre attached.

\section{Materials and methods}

\subsection{Formation of glass}

The $60 \mathrm{P}_{2} \mathrm{O}_{5} \cdot 20 \mathrm{CaO} \cdot(20-x) \mathrm{Na}_{2} \mathrm{O} \cdot x \mathrm{Ag}_{2} \mathrm{O}$ with $x=0,0.3,0.5,0.8$ and $1 \mathrm{~mol} \%$ bioactive glasses were prepared by the conventional melt quenching method using $\mathrm{NH}_{4} \cdot \mathrm{H}_{2} \mathrm{PO}_{4}, \mathrm{CaCO}_{3}$, $\mathrm{Na}_{2} \mathrm{CO}_{3} \cdot 10 \mathrm{H}_{2} \mathrm{O}$ and $\mathrm{AgNO}_{3}$ as starting materials. The mixtures corresponding to the desired compositions were melted in air, in sintered corundum crucibles, in an electric furnace at $1200{ }^{\circ} \mathrm{C}$ for $30 \mathrm{~min}$. The melted mixtures were then quickly cooled at room temperature by pouring and pressing between two copper plates.

Contact angle was measured using drop shape analysis in the sessile drop method with $2 \mu \mathrm{l}$ water for the characterization of the surfaces.

\subsection{Protein adsorption}

Bovine serum albumin (BSA) (Sigma-Aldrich, molar mass $69 \mathrm{kDa}$ ) solutions of different concentrations were prepared in phosphate buffer solution (PBS) pH 7.4 to test protein adsorption by means of different investigation methods. Before protein adsorption, the samples were cleaned with plasma cleaner.

Glass powders for FT-IR and glass pieces for AFM measurements were immersed in BSA solutions of $100 \mu \mathrm{M}(\sim 6.9 \mathrm{mg}$ $\left.\mathrm{ml}^{-1}\right)$ and $7 \mu \mathrm{M}\left(\sim 0.5 \mathrm{mg} \mathrm{ml}{ }^{-1}\right)$, respectively, and afterwards placed in an incubator at a constant temperature of $37^{\circ} \mathrm{C}$ for 30 min. The solution was then removed from the samples, rinsed three times with PBS, and air dried.

For the spin labeling procedure, a solution of $100 \mu \mathrm{M}$ bovine serum albumin in phosphate buffer ( $\mathrm{pH}$ 7.4) was incubated for 48 hours at $37{ }^{\circ} \mathrm{C}$ with 6 -fold molar excess of (4-(2-iodoacetamido)-2,2,6,6-tetramethyl-1-piperidinyloxy) spin label. Unbound IA was removed by repeated dilution steps with sodium phosphate buffer, $\mathrm{pH}$ 7.4, using centrifugal filter units with $30 \mathrm{kDa}$ molecular weight cut-off (Amicon/Millipore, Carrigtwohill, Co. Cork, Ireland). Labeling efficiency (spin label per protein molecule) was determined to be $100 \%( \pm 5 \%)$. 
Considering the location of the Cys34 residue, which is hidden in a hydrophobic crevice and, therefore, not so easily accessible, we assume that this high value of spin label efficiency is given by the additional labeling of other thiol groups. BSA has 35 cysteines in total, 34 of them being involved in disulphide bridges. It was previously shown that between $\mathrm{pH} 7$ and $\mathrm{pH}$ 10, a gradual reduction of $\mathrm{S}-\mathrm{S}$ bonds occurs in bovine serum albumin, so that up to three disulfide bonds are reducible in the protein, thus becoming available for spin labeling. ${ }^{32,33}$

For protein adsorption experiments, the glass pieces were milled to micrometric-sized particles. The powder samples $(150 \mathrm{mg})$ were afterwards incubated for $30 \mathrm{~min}$ at $37^{\circ} \mathrm{C}$ in spinlabeled BSA solution $(100 \mu \mathrm{M})$. Afterwards, the samples were washed three times with buffer solution to remove the unattached protein molecules.

\subsection{Methods}

X-ray Diffraction. The X-ray diffraction analysis was carried out on a Shimadzu XRD-6000 diffractometer using $\mathrm{CuK} \alpha$ radiation $(\lambda=1.54)$, with an Ni-filter.

UV-vis Spectroscopy. Absorption measurements were performed with an Analytic Jena Specord 250 plus UV-Vis spectrometer. The spectral resolution was of $2 \mathrm{~nm}$.

X-Ray Photoelectron Spectroscopy. The XPS spectra were recorded with a SPECS PHOIBOS 150 MCD system employing a monochromatic $\mathrm{Al}-\mathrm{K}_{\alpha}$ source (1486.6 eV), a hemispherical analyser and charge neutralization device. Samples were fixed on double-sided carbon tape, and care was taken to ensure that the sample particles covered the tape. Experiments were performed by operating the X-ray source with a power of $250 \mathrm{~W}$, while the pressure in the analyser chamber was in the range of $10^{-9}-10^{-10}$ mbar. The binding energy scale was charge referenced to the $\mathrm{C} 1 \mathrm{~s}$ at $284.6 \mathrm{eV}$. Further, elemental composition was determined from the survey spectra acquired at pass energy of $100 \mathrm{eV}$. High resolution spectra were obtained using analyzer pass energy of $30 \mathrm{eV}$. Analysis of the data was carried out with Casa XPS software. A Shirley background was used for all curvefitting along with the Gaussian/Lorentzian product form $(70 \%$ Gaussian and 30\% Lorentzian).

FT-IR Spectroscopy. The FT-IR spectra of the glass samples were recorded in reflection configuration in the range 4000-400 $\mathrm{cm}^{-1}$ with spectral resolution of $4 \mathrm{~cm}^{-1}$ using a Jasco FT-IR6000 spectrometer and $\mathrm{KBr}$ pellet technique. The FT-IR spectra of glasses after protein adsorption were recorded using a Jasco IRT-5000 FT-IR microscope coupled to a Jasco FT-IR-6000 spectrometer in reflection configuration in the range 4000-650 $\mathrm{cm}^{-1}$ with a resolution of $4 \mathrm{~cm}^{-1}$, using the $32 \times$ Cassegrain objective to image a sample area of $\sim 50 \times 50 \mu \mathrm{m}^{2}$. The recorded spectra were smoothed by a 9-point Savitzky-Golay smoothing function for background correction. Second-derivative spectral analysis was performed by using the JASCO Spectra Manager in order to locate the position of the overlapped components of amide I, which were further assigned to different secondary structures. In addition, the bands were deconvoluted with a Gaussian band profile, a linear baseline between $1600 \mathrm{~cm}^{-1}$ and $1710 \mathrm{~cm}^{-1}$ being previously applied. The secondary structure composition was determined from the areas of the individually assigned components and their fraction of the total area.

EPR Spectroscopy. X band CW-EPR experiments were performed using a commercially available Mini Scope benchtop EPR spectrometer (MS200; Magnettech GmbH, Berlin, Germany) with a rectangular TE102 resonator. Due to heat production in the resonator during operation, the sample environment was fluxed with gaseous nitrogen, keeping the temperature stable. The spectrometer settings were as follows: the microwave power was set to $10 \mathrm{~mW}$; the B-field modulation amplitude was $0.15 \mathrm{mT}$. EPR glass capillaries of $1 \mathrm{~mm}$ inner diameter (i.d.) were filled with sample volumes of $20 \mu \mathrm{l}$, considering that the EPR active volume of the sample tube is $\mathbf{1 5}$ $\mu \mathrm{l}$. The integrated EPR absorption signal is directly proportional to the spin concentration in the sample and was used to calculate the amount of the protein attached to the investigated systems. As reference spin probe, 2,2,6,6-tetramethyl-1-piperidinyloxy (TEMPO) of $100 \mu \mathrm{M}$ concentration was used.

Atomic Force Microscopy. AFM measurements were carried out on an Asylum MFP-3D head and controller (Asylum Research, Santa Barbara, CA). The driver program MFP-3D Xop was written in IGOR Pro software (version 5.04b, Wavemetrics, Lake Oswego, OR). The measurements were carried out with AC240 rectangular silicon cantilevers, with tetrahedral tips (Olympus, Optical Co. Ltd. Tokyo, Japan). The spring constant for each cantilever was determined by thermal calibration. ${ }^{34}$ The measurements were carried out in AC (semicontact) mode in air at room temperature. Typically, $512 \times 512$ point scans were taken at a scan rate of $1 \mathrm{~Hz}$ per line. Both trace and retrace images were recorded and compared.

\section{Results and discussion}

\subsection{Structural characterization}

The obtained samples with $60 \mathrm{P}_{2} \mathrm{O}_{5} \cdot 20 \mathrm{CaO} \cdot(20-x)$ $\mathrm{Na}_{2} \mathrm{O} \cdot x \mathrm{Ag}_{2} \mathrm{O}(x=0,0.3,0.5,0.8$ and $1 \mathrm{~mol} \%)$ composition prepared by a conventional melt quenching method were transparent and colourless. The X-ray diffraction patterns consist of a very broad peak (Fig. 2) and confirm the vitreous character of all samples.

In order to obtain further insight into the structure of the investigated glass samples, UV-vis absorption spectra were recorded. The silver atoms, ions, and clusters exhibit different optical properties that can be evidenced by means of UV-vis spectroscopy. Thus, the electronic transitions involving the $\mathrm{Ag}^{+}$ ion are visible in the 190-230 $\mathrm{nm}$ spectral range, and the electronic transitions of metallic $\mathrm{Ag}^{0}$ appear in the $250-330 \mathrm{~nm}$ spectral range, while isolated and aggregated $\mathrm{Ag}$ nanoparticles absorb at wavelengths higher than $400 \mathrm{~nm} .^{23,35,36}$ The UV-vis absorption spectra recorded for the investigated samples evidenced absorption bands only for the silver containing glasses (Fig. 3). The glasses with lower concentration of silver $(x=0.3$ and 0.5) exhibit only absorption bands in the 190-230 nm spectral range, associated with the presence of $\mathrm{Ag}^{+}$ion, although the sample containing $0.5 \mathrm{~mol}^{\mathrm{m}} \mathrm{AgO}_{2}$ slightly exhibits the presence of metallic $\mathrm{Ag}^{0}$. However, as the silver amount increases $(x=0.8$ and 1$)$ close to the absorption band recorded 


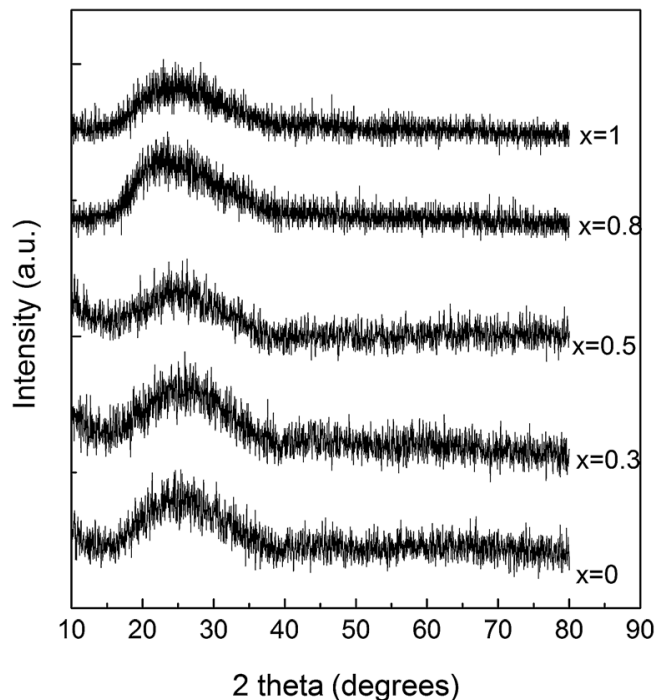

Fig. 2 XRD patterns of the $60 \mathrm{P}_{2} \mathrm{O}_{5} \cdot 20 \mathrm{CaO} \cdot(20-x) \mathrm{Na}_{2} \mathrm{O} \cdot x \mathrm{Ag}_{2} \mathrm{O}$ glass samples.

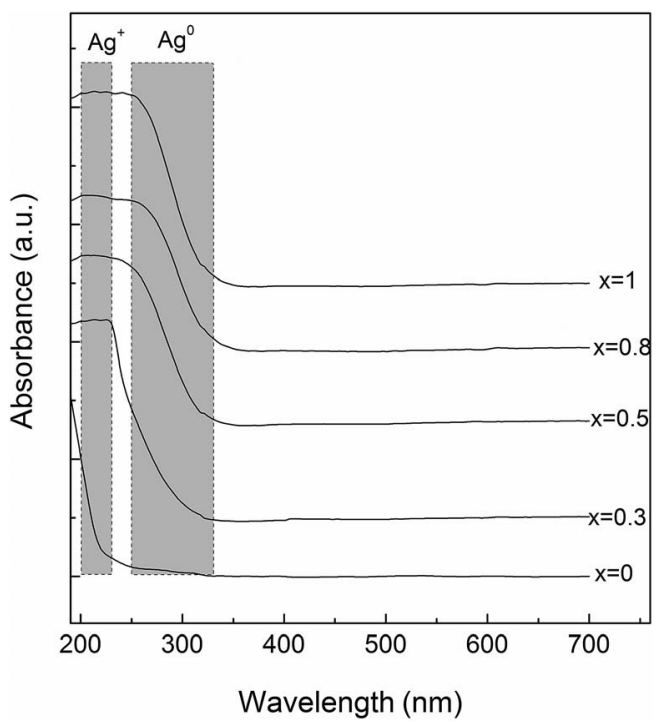

Fig. $3 \mathrm{UV}$-vis spectra of the $60 \mathrm{P}_{2} \mathrm{O}_{5} \cdot 20 \mathrm{CaO} \cdot(2 \mathrm{O}-x) \mathrm{Na}_{2} \mathrm{O} \cdot x \mathrm{Ag}_{2} \mathrm{O}$ glass samples.

for the $\mathrm{Ag}^{+}$ion, the UV-vis spectra reveal the presence of the metallic $\mathrm{Ag}^{0}$, as shown by the presence of the electronic absorption signal that occurs in the $250-300 \mathrm{~nm}$ spectral range.

To investigate the chemical state of silver in these glasses, an XPS analysis was performed. The Ag $3 \mathrm{~d}$ spectrum consists of a doublet for the $\mathrm{Ag} \mathrm{d}_{5 / 2}$ and $\mathrm{Ag} \mathrm{d}_{3 / 2}$ components due to spinorbit splitting, at the binding energies of 368.6 and $374.6 \mathrm{eV}$, respectively (Fig. 4). ${ }^{23,37,38}$ To further examine the chemical state of silver in the investigated glass with $0.5,0.8$ and $1 \mathrm{~mol} \% \mathrm{Ag}_{2} \mathrm{O}$, the $\mathrm{Ag} 3 \mathrm{~d}$ photoelectron peaks were deconvoluted. Silver content of the glass with $0.3 \% \mathrm{Ag}_{2} \mathrm{O}$ is very small; thus the deconvolution could not be performed. For the $\mathrm{Ag} \mathrm{d}_{5 / 2}$ component, two contributions were considered centred at binding

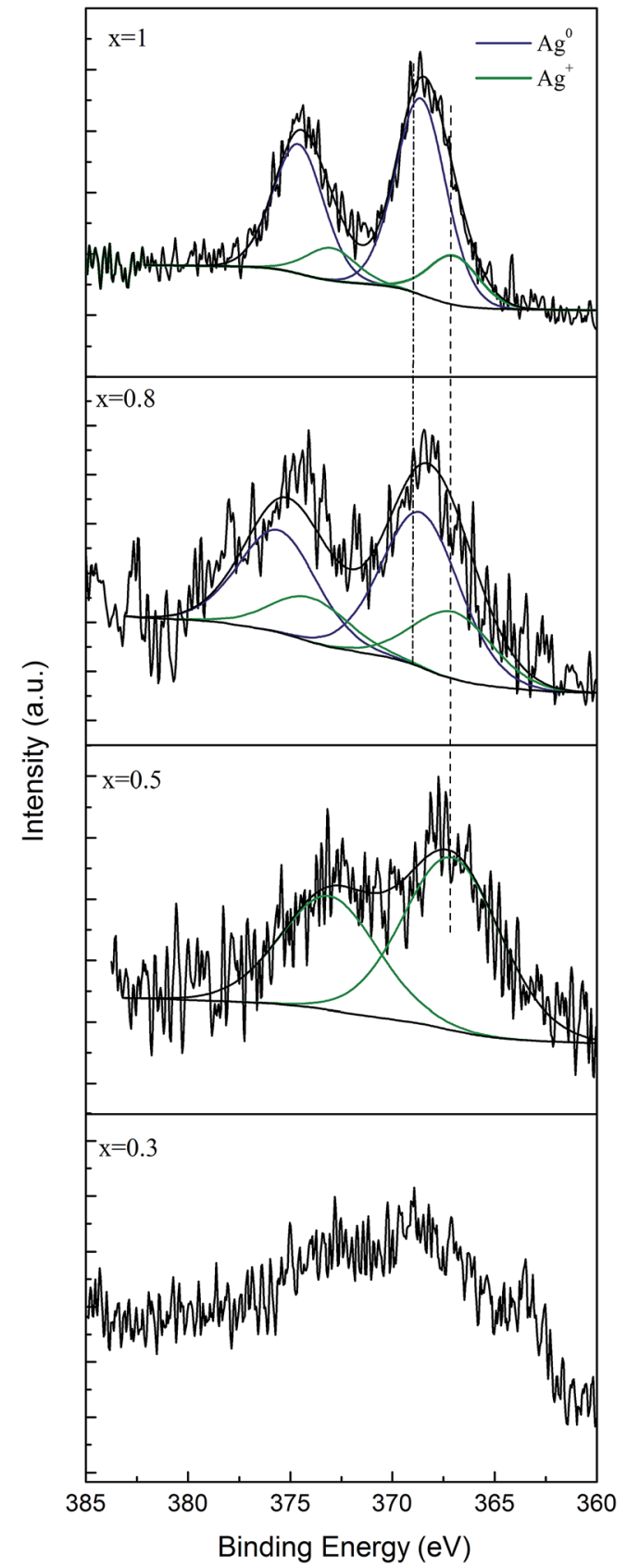

Fig. 4 Deconvolution of $\mathrm{Ag} 3 \mathrm{~d}$ XPS spectra of the $60 \mathrm{P}_{2} \mathrm{O}_{5} \cdot 20 \mathrm{CaO} \cdot(20-x) \mathrm{Na}_{2} \mathrm{O} \cdot x \mathrm{Ag}_{2} \mathrm{O}$ glass samples.

energies of 368.6 and $367.2 \mathrm{eV}$ and are assigned to $\mathrm{Ag}^{0}$ and $\mathrm{Ag}^{+}$, respectively. ${ }^{37}$ By calculating the peak area ratios of the deconvoluted peaks in the sample with $x=0.8$, it was determined that about $66.71 \%$ of the silver atoms are in the $\mathrm{Ag}^{0}$ chemical state, while $32.7 \%$ are in the $\mathrm{Ag}^{+}$chemical state. Higher percentage of metallic $\mathrm{Ag}^{0}(87.1 \%)$ is in turn present in the sample with $x=1$. The deconvolution of Ag $3 \mathrm{~d}$ photoelectron peaks for the sample containing $0.5 \mathrm{~mol} \%$ silver oxide provides only one component, attributed to the $\mathrm{Ag}^{+}$chemical state. These findings confirm the results obtained by UV-vis spectroscopy, i.e. with increasing the silver content in the glass, the amount of metallic silver increases. 
The FT-IR spectra of the obtained glass samples have characteristic absorption bands of phosphate based glasses (Fig. 5). ${ }^{6,8,36,39-41}$ The bands in the region $400-600 \mathrm{~cm}^{-1}$ can be attributed to bending vibrations of bridging phosphorus such as $\mathrm{O}-\mathrm{P}-\mathrm{O}$ and/or $\mathrm{O}=\mathrm{P}-\mathrm{O} .^{6,39,40}$ The IR bands and shoulders observed at around 772 and $715 \mathrm{~cm}^{-1}$ for $x=0$ are attributed to the $\mathrm{P}-\mathrm{O}-\mathrm{P}$ bending and asymmetric vibrations, respectively. ${ }^{\mathbf{4 0 , 4 1}}$

The absorption band at around $905 \mathrm{~cm}^{-1}$ is attributed to the $\left(\mathrm{PO}_{4}\right)^{3-}$ symmetric stretching vibrations, indicating that a considerable part of the phosphate network still remains linked even after an addition of a relatively high amount of silver. ${ }^{36}$ The band observed at around $1280 \mathrm{~cm}^{-1}$ can be assigned to the $\mathrm{P}=\mathrm{O}$ stretching vibrations, ${ }^{40}$ while the bands at approximately $1100 \mathrm{~cm}^{-1}$ and at $1020 \mathrm{~cm}^{-1}$ are due to the $\left(\mathrm{PO}_{3}\right)^{2-}$ stretching vibrations. ${ }^{36,40}$

\subsection{Protein adsorption}

Wettability of the surface plays an important role in the conformational changes that a protein undergoes during adsorption on a surface. In order to clarify this aspect, the contact angle of the studied surfaces was measured. Since in all the cases the value determined for the contact angle was $37^{\circ} \pm 3^{\circ}$, one can infer that the used $\mathrm{Ag}_{2} \mathrm{O}$ content does not affect the hydrophobic character of the surface.

After BSA adsorption, the FT-IR spectra of the samples containing $\mathrm{Ag}_{2} \mathrm{O}$ show the presence of the two characteristic bands of proteins: amide I band at $1650 \mathrm{~cm}^{-1}$ and amide II band at $1550 \mathrm{~cm}^{-1}$ (Fig. 6). The integrated area of amide I of BSA adsorbed onto the glass surfaces was normalized to the absorption band at $1280 \mathrm{~cm}^{-1}$ and subjected to quantitative comparison (Fig. 7) by assuming that there is a small probability that this type of vibration will be affected by the silver addition. The maximum value of the integrated area has been obtained for the sample with $0.5 \mathrm{~mol} \%$ silver oxide content.

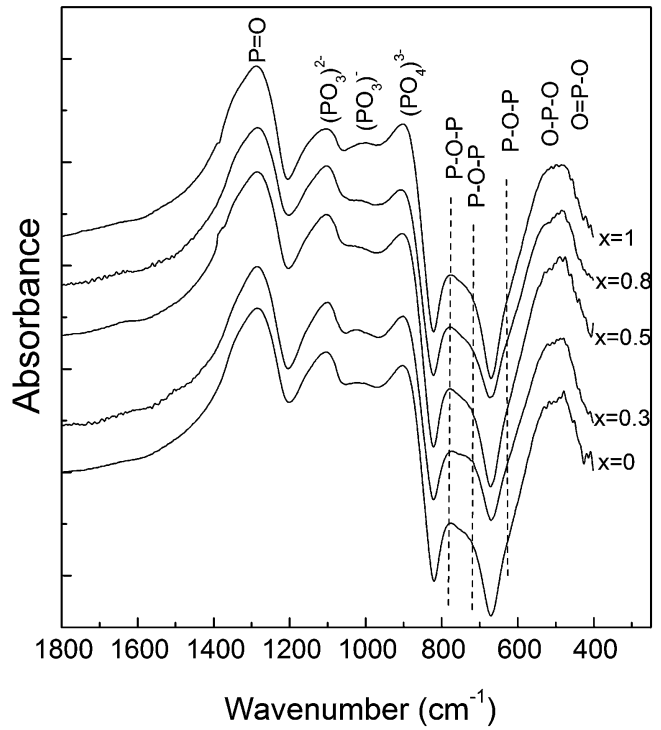

Fig. 5 FT-IR spectra of the $60 \mathrm{P}_{2} \mathrm{O}_{5} \cdot 20 \mathrm{CaO} \cdot(20-x) \mathrm{Na}_{2} \mathrm{O} \cdot x \mathrm{Ag}_{2} \mathrm{O}$ glass samples.

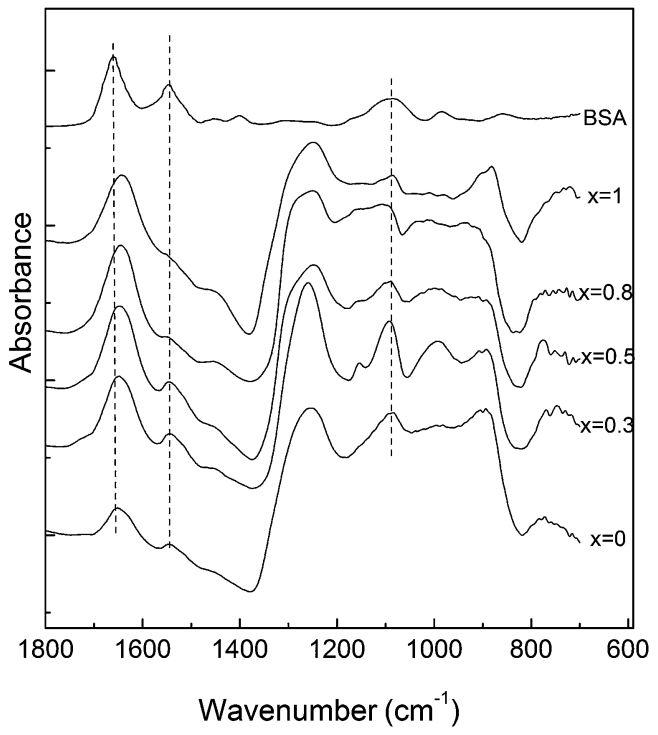

Fig. 6 FT-IR spectra of the $60 \mathrm{P}_{2} \mathrm{O}_{5} \cdot 20 \mathrm{CaO} \cdot(20-x) \mathrm{Na}_{2} \mathrm{O} \cdot x \mathrm{Ag}_{2} \mathrm{O}$ glass samples after BSA adsorption.

It was reported that the change of the intensities ratio of amide I/II bands indicates that the secondary structure of the protein may be affected. ${ }^{\mathbf{1 1}, 42}$ In the case of the investigated samples, the amide I/II intensity ratio increases progressively (from 2.1 for $0.5 \mathrm{~mol} \% \mathrm{Ag}_{2} \mathrm{O}$ to 2.7 for $1 \mathrm{~mol} \% \mathrm{Ag}_{2} \mathrm{O}$ ), suggesting that the secondary structure of the protein is gradually, more intensely affected, as the silver content increases. The most important question that arises now is related to the role played by the silver content on the induced conformational changes. In order to get more insights into the mentioned aspect, EPR measurements were further performed.

The EPR spectrum of spin-labeled BSA reveals the presence of two spectral components clearly visible in the lower field spectral line (Fig. 8). As discussed in the Materials and Methods section, besides the free thiol at position 34 , additional cysteines were labeled, as one to three disulphide bonds were broken in each protein, as a consequence of the $\mathrm{pH}$ value used. Component I (immobile) represents a fraction of the nitroxide population having the spin label reorientational freedom restricted due to secondary and tertiary interactions, as result of Cys34 location in a hydrophobic crevice of 9.5-10 ̊ in depth ${ }^{43}$ and/or the local restrictions of the other labelled disulphide bridges (it was previously shown that all 17 disulphide bonds in BSA have buried locations within the protein molecule ${ }^{26}$ ). The resulting EPR spectrum is characterized by broad lines and large apparent hyperfine splittings. In contrast, component $\mathbf{M}$ (mobile) is characterized by narrow linewidth of the central line and small apparent hyperfine splitting, representing a nitroxide subpopulation with higher spin label mobilities, indicating that the nitroxide moiety is more free in the solvent.

Upon adsorption on the sample's surface, the immobile component increases at the expense of the mobile component (see inset of Fig. 8), evidencing local conformational changes in the vicinity of the labeled cysteines, as consequence of the adsorption process. The linewidth increase observed in the 

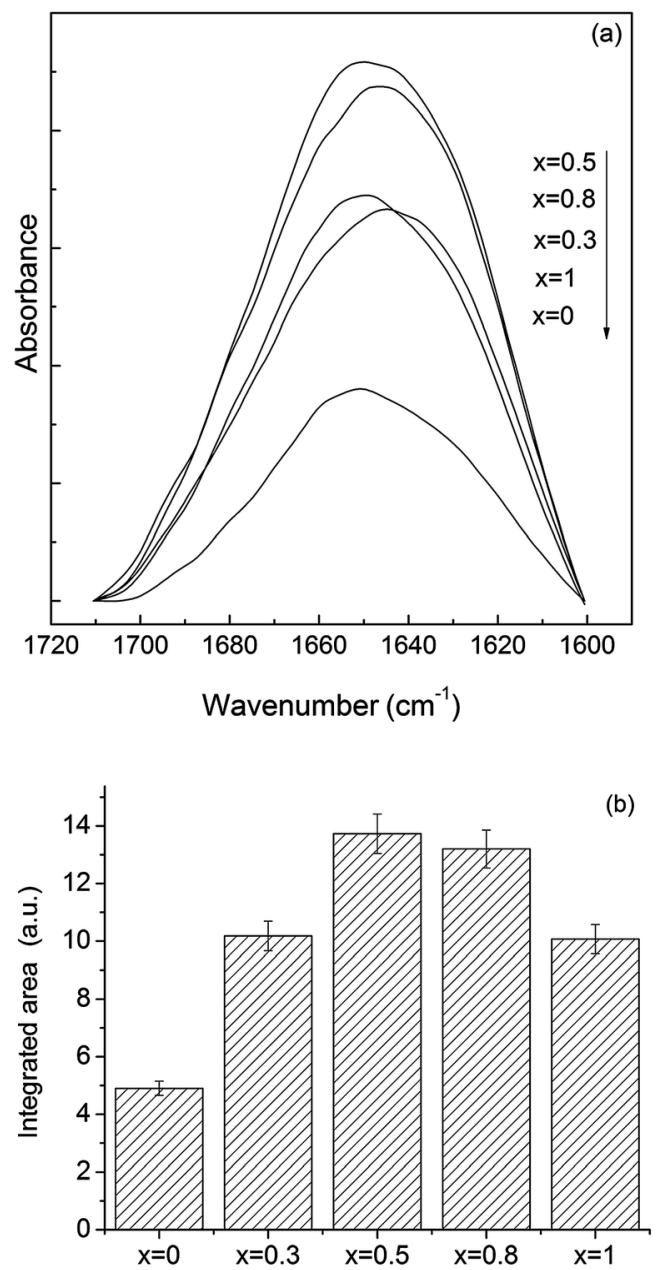

Fig. 7 FT-IR spectra (a) and integrated area (b) of the amide I absorption band of BSA recorded after adsorption onto $60 \mathrm{P}_{2} \mathrm{O}_{5} \cdot 20 \mathrm{CaO} \cdot(20-x) \mathrm{Na}_{2} \mathrm{O} \cdot x \mathrm{Ag}_{2} \mathrm{O}$ glass surfaces and normalized to the absorption band at $1280 \mathrm{~cm}^{-1}$. The normalized amide I absorption bands are displayed in descending order, as shown by the arrow.

lower field spectral line for all the EPR spectra recorded in the adsorbed state (shown by the arrow in Fig. 8) suggests that the movement of the entire BSA molecule is hampered by interactions with the substrate samples. As silver concentration increases, the EPR spectra show stronger immobilization of spin labels on the substrate, indicating an enhanced interaction of the BSA molecule on the samples with higher silver content. This behaviour was previously reported on methemoglobin attached on silver-containing bioactive glass, and it was attributed to the interaction between silver ions and thiol groups in proteins. ${ }^{23,24}$ Another study also emphasized the strong interaction between silver nanoparticles and sulphur-containing peptides/amino acids. ${ }^{44}$ Since the free thiol groups in the BSA molecule were blocked by the spin label, we assume that additional thiol groups involved in disulfide bridges in the BSA molecule are broken during the adsorption process. The aggressiveness of this process is strongly dependent on the silver content in the sample: over $0.5 \mathrm{~mol} \% \mathrm{Ag}_{2} \mathrm{O}$, the protein

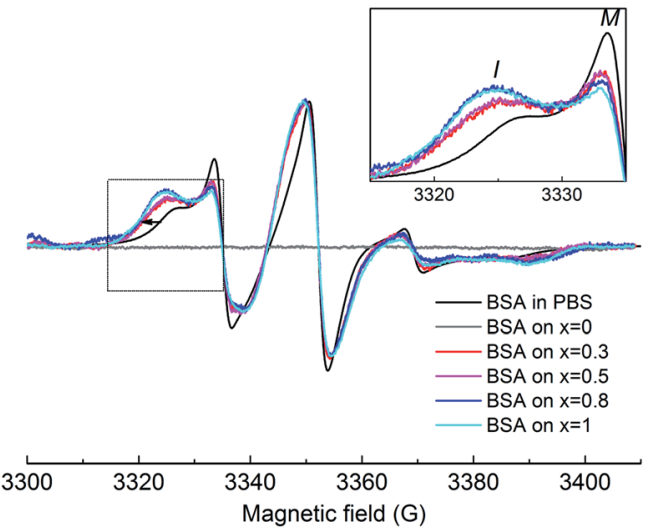

Fig. 8 Room temperature CW-EPR spectra of spin-labeled BSA after adsorption on the investigated samples, normalized to amplitude. Upper right inset: the low field spectral line of the normalized CW-EPR spectra recorded for spin-labeled BSA before (black) and after adsorption onto the investigated samples. The grey line was recorded for BSA-adsorbed sample containing 0\% Ag. The black arrow shows the linewidth increase of the low field line after adsorption. The mobile and immobile components visible in the lower field spectral lines are depicted with $M$ and I, respectively (inset).

suffers more severe conformational changes. It may be possible that in samples with higher silver content $(0.8$ and $1 \mathrm{~mol} \%$ $\mathrm{Ag}_{2} \mathrm{O}$ ), the surroundings of the labelled cysteines are completely unfolded, and thus, these regions have direct contact with the bioactive glass surface. This would imply that at silver oxide contents higher than $0.5 \mathrm{~mol} \%$, the interaction between bioactive glass and BSA results in the unfolding of a large fraction of the protein structure. Furthermore, the amount of the protein attached to the sample can be also interpreted as a result of the strong interaction owed to the presence of silver in the sample. As silver content increases, more protein attaches on the sample's surface (see Fig. 9). Furthermore, no protein was found to be attached to the sample without silver content, most probably because the marker concentration from the adsorbed protein was under the detection limit. This is clear evidence that the main interaction between the BSA molecule

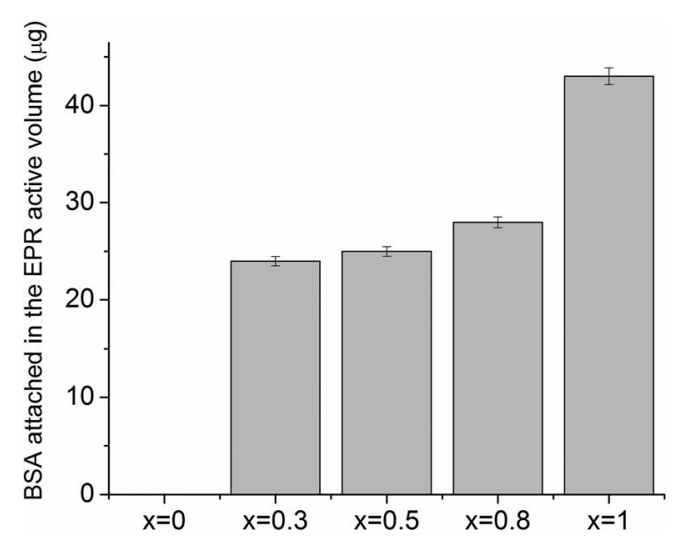

Fig. 9 BSA attached in the EPR active volume $(\mu \mathrm{g})$ after adsorption onto the investigated samples. Errors are estimated to $\pm 2 \%$, due to experimental settings and uncertainties in baseline subtraction. 
and the sample's surface occurs especially through the medium of silver ions. On the other hand, the lack of a signal from the protein attached on the silver-free glass suggests that the best way of interpreting the achieved data is from a qualitative perspective.

The secondary structure conformation of BSA after adsorption on the glass surfaces was analysed by deconvolution of the amide I absorption band from the FT-IR spectrum. ${ }^{42}$ The secondary structure of lyophilized BSA is typical, dominated by $\alpha$ helices (1649-1657 $\mathrm{cm}^{-1}$ ), but it also contains a small amount of $\beta$-sheet (1618-1641 and 1674-1695 $\left.\mathrm{cm}^{-1}\right)$ and $\beta$-turn (1662$1686 \mathrm{~cm}^{-1}$ ) structure. ${ }^{45}$ After adsorption, in all cases, a new band appears around $1608 \mathrm{~cm}^{-1}$ that can be associated with the existence of $\beta$-sheet aggregation/amino acid side chain residues. ${ }^{46}$ The secondary structure of BSA, after its adsorption on the glass with $0.5 \mathrm{~mol} \% \mathrm{Ag}_{2} \mathrm{O}$, evidenced only minor changes that are within the error limit. In contrast, in the case of samples with 0.8 and $1 \mathrm{~mol} \% \mathrm{Ag}_{2} \mathrm{O}$, one can observe that BSA loses a large fraction of its helical structure, and a concurrent increase in $\beta$-sheet and $\beta$-turn structural components occurs (Fig. 10 and 11). These results support the hypothesis highlighted by EPR spectroscopy that a large fraction of the protein structure is unfolded on the bioactive glasses with silver contents higher than $0.5 \mathrm{~mol} \%$. Interestingly, the UV-vis spectra showed that metallic $\mathrm{Ag}^{0}$ appears in these samples (Fig. 3). Regarding the sample without silver oxide content, one

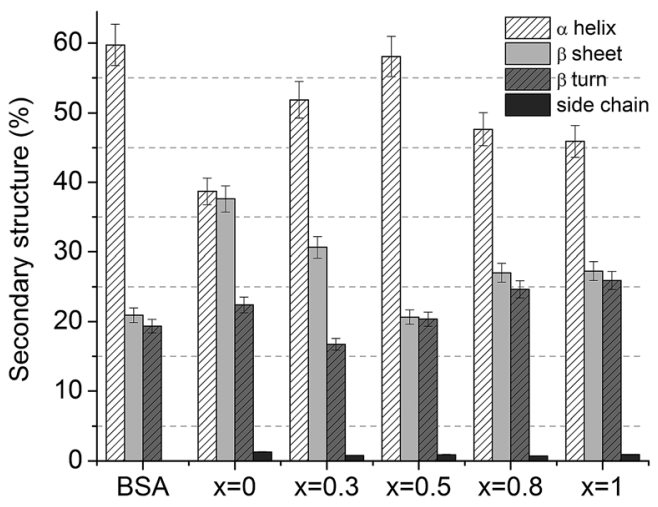

Fig. 11 Distribution of secondary structures in lyophilized and adsorbed BSA onto $60 \mathrm{P}_{2} \mathrm{O}_{5} \cdot 20 \mathrm{CaO} \cdot(20-x) \mathrm{Na}_{2} \mathrm{O} \cdot x \mathrm{Ag}_{2} \mathrm{O}$ glass samples' surfaces.

observes that the secondary structure of BSA is affected as a consequence of a small amount of protein adsorption.

To visualize the BSA adsorption on the glass surfaces, the AFM technique was used (Fig. 12). In order to compare the surface changes induced by BSA adsorption, the surface roughness was determined from $1 \times 1 \mu \mathrm{m}^{2}$ images (Fig. 13). ${ }^{47,48}$ The AFM images revealed that the surface roughness begins to increase with the addition of silver oxide in the glasses, peaking at $0.5 \mathrm{~mol} \%$, after which it begins to decrease (Fig. 13). These
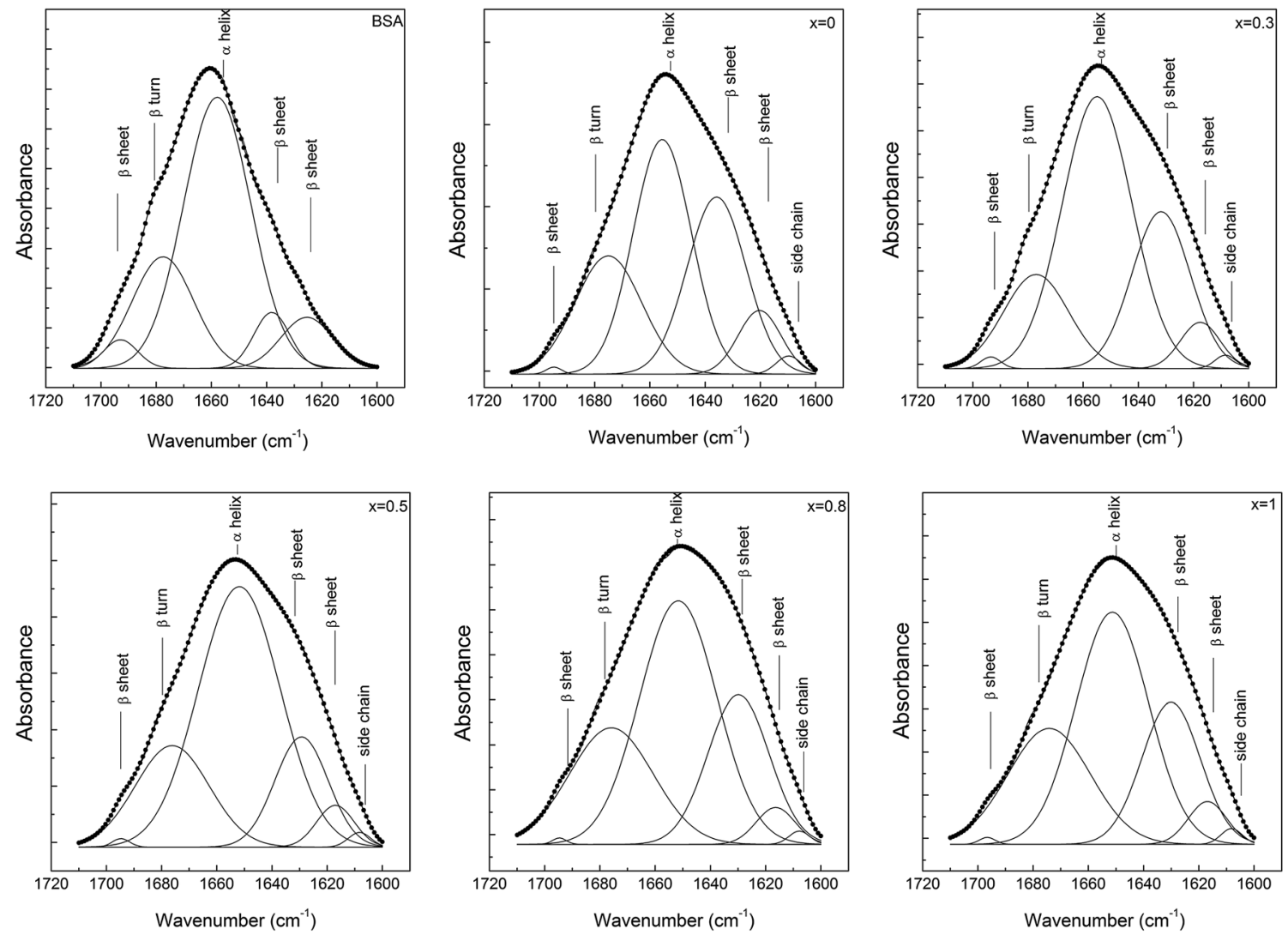

Fig. 10 Deconvolution of the amide I $\left(1700-1600 \mathrm{~cm}^{-1}\right)$ absorption band of the lyophilized BSA, before and after its adsorption on the bioactive $60 \mathrm{P}_{2} \mathrm{O}_{5} \cdot 20 \mathrm{CaO} \cdot(2 \mathrm{O}-x) \mathrm{Na}_{2} \mathrm{O} \cdot x \mathrm{Ag}_{2} \mathrm{O}$ glass samples' surfaces. 

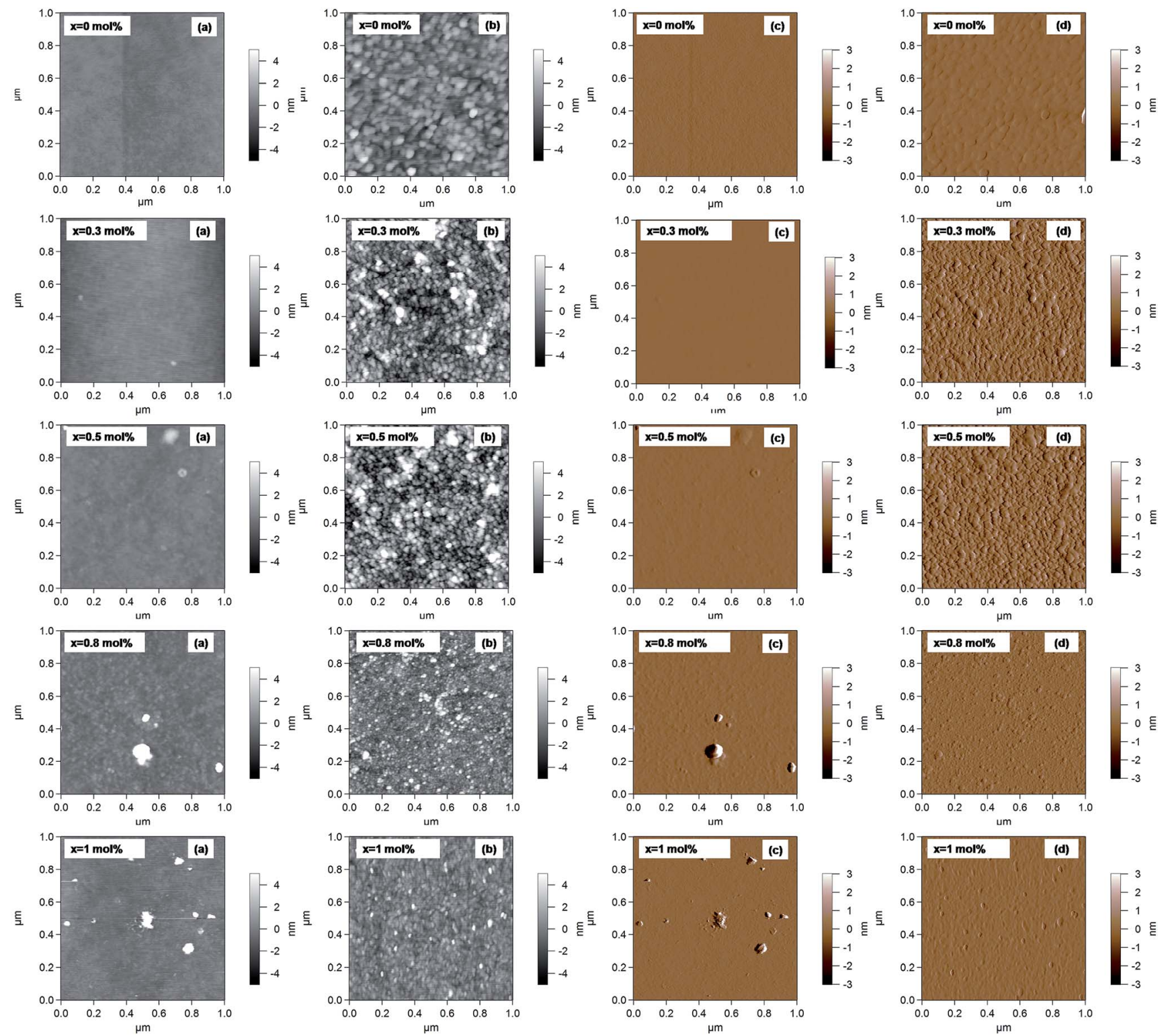

Fig. $12 \mathrm{AFM}$ images of the $60 \mathrm{P}_{2} \mathrm{O}_{5} \cdot 20 \mathrm{CaO} \cdot(20-x) \mathrm{Na}_{2} \mathrm{O} \cdot x \mathrm{Ag}_{2} \mathrm{O}$ glass samples; height images before adsorption (a); height images after $\mathrm{BSA}$ adsorption (b); amplitude images before adsorption (c) and amplitude images after BSA adsorption (d).

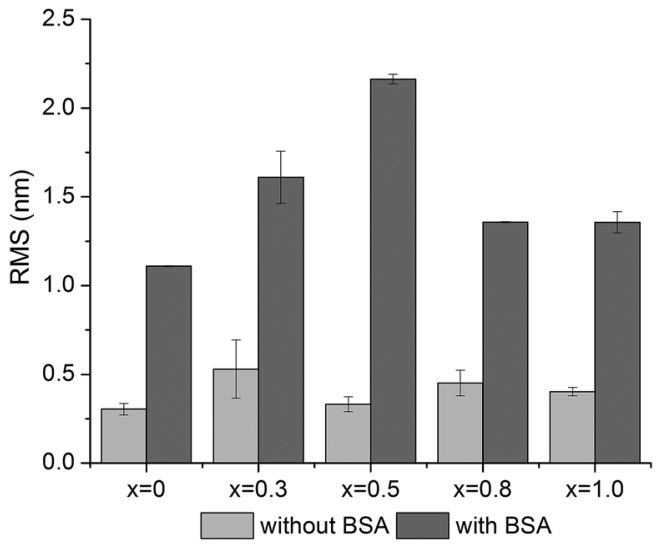

Fig. 13 Root-mean-square (RMS) roughness before and after BSA adsorption determined by AFM from $1 \times 1 \mu \mathrm{m}^{2}$ images. results support the hypothesis highlighted by FT-IR and EPR spectroscopy, namely that the BSA structure unfolds on the high $(x=0.8$ and $x=1$ ) silver content samples. The attached protein layer is, therefore, more uniform on these two samples, resulting in an increase of surface smoothness.

All results presented in this study suggest that increasing the silver content in glass samples increases albumin adsorption on the surface, but metallic $\mathrm{Ag}^{0}$ appearance in the glass samples affects the protein secondary structure. This is in agreement with results obtained by other research groups that silver ions are active species in the biological system, since BSA can bind free silver ions, thus reducing its cellular toxicity. ${ }^{17}$ Negatively charged surfaces such as $\mathrm{OH}, \mathrm{SH}$ and $\mathrm{COOH}$, which activate the coagulation cascade via adsorption on various sites like those represented by the silver species, could also represent a possible 
reason for the important conformational change of the protein that appears for high silver content. Nevertheless, for the deep understanding of the role played by the silver amount present in the composition of a bioactive glass on protein conformational changes, other detailed investigations are needed.

\section{Conclusions}

The $60 \mathrm{P}_{2} \mathrm{O}_{5} \cdot 20 \mathrm{CaO} \cdot(20-x) \mathrm{Na}_{2} \mathrm{O} \cdot x \mathrm{Ag}_{2} \mathrm{O}(0 \leq x \leq 1 \mathrm{~mol} \%)$ meltderived bioactive glass system was studied with respect to the influence of silver content on serum albumin adsorption. The XPS and UV-vis spectra revealed that in the samples with the lowest $\mathrm{Ag}_{2} \mathrm{O}$ content ( $x=0.3$ and 0.5 ), only $\mathrm{Ag}^{+}$ions are present, while metallic $\mathrm{Ag}^{0}$ starts to appear for $\mathrm{Ag}_{2} \mathrm{O}$ content exceeding $0.8 \mathrm{~mol} \%$. Room temperature EPR spectra of spin-labelled protein revealed that silver content in the sample increases the adsorption potential of albumin on the sample's surface. Nevertheless, the appearance of metallic $\mathrm{Ag}^{0}$ in samples with 0.8 and $1 \mathrm{~mol} \% \mathrm{Ag}_{2} \mathrm{O}$ results in severe alteration of the BSA secondary structure, as a consequence of protein unfolding, and this effect was revealed by EPR, FT-IR spectroscopy and AFM. All results presented here suggest that the optimal silver oxide concentration in the investigated bioactive glass system for which the secondary structure of the adsorbed protein is similar with that of free protein is $0.5 \mathrm{~mol} \%$. This silver content represents the best compromise for the two important issues related to the protein adsorption process on the involved bioactive glass surface: the amount of the attached protein and the lack of conformational changes induced in the protein structure.

\section{Acknowledgements}

CG and HJS gratefully acknowledge the support by the DAAD programme "Ostpartnerschaften".

\section{References}

1 J. J. Blaker, A. R. Boccaccini and S. N. Nazhat, J. Biomater. Appl., 2005, 20, 81-98.

2 M. Bellantone, H. D. Williams and L. L. Hench, Antimicrob. Agents Chemother., 2002, 46, 1940-1945.

3 S. S. Djokie and R. E. Burrell, J. Electrochem. Soc., 1998, 145, 1426-1431.

4 S. Di Nunzio, C. Vitale Brovarone, S. Spriano, D. Milanese, E. Verné, V. Bergo, G. Maina and P. Spinelli, J. Eur. Ceram. Soc., 2004, 24, 2935-2942.

5 A. Hoppe, N. S. Guldal and A. R. Boccaccini, Biomaterials, 2011, 32, 2757-2774.

6 A. A. Ahmed, A. A. Ali, D. A. R. Mahmoud and A. M. El-Fiqi, Solid State Sci., 2011, 13, 981-992.

7 V. Simon, C. Albon and S. Simon, J. Non-Cryst. Solids, 2008, 354, 1751-1755.

8 R. Ciceo Lucacel, A. O. Hulpus, V. Simon and I. Ardelean, J. Non-Cryst. Solids, 2009, 355, 425-429.
9 R. A. Latour, in The Encyclopedia of Biomaterials and Bioengineering, ed. G. E. Wnek and G. L. Bowlin, Taylor \& Francis, New York, 2005, pp. 1-15.

10 K. Wang, C. Zhou, Y. Hong and X. Zhang, Interface Focus, 2012, 2, 259-277.

11 P. Roach, D. Farrar and C. C. Perry, J. Am. Chem. Soc., 2005, 127, 8168-8173.

12 X. M. He and D. C. Carter, Nature, 1992, 358, 209-2015.

13 E. Vanea, K. Magyari and V. Simon, J. Optoelectron. Adv. Mater., 2010, 12, 1206-1212.

14 K. Magyari, O. Popescu and V. Simon, J. Mater. Sci.: Mater. Med., 2010, 21, 1913-1920.

15 K. Magyari, L. Baia, O. Popescu, S. Simon and V. Simon, Vib. Spectrosc., 2012, 62, 172-179.

16 N. Shahabadi, M. Maghsudi and Z. Ahmadipour, Spectrochim. Acta, Part A, 2012, 92, 184-188.

17 S. Kittler, C. Greulich, J. S. Gebauer, J. Diendorf, L. Treuel, L. Ruiz, J. M. Gonzalez-Calbet, M. Vallet-Regi, R. Zellner, M. Koller and M. Epple, J. Mater. Chem., 2010, 20, 512-518.

18 R. Liu, F. Sun, L. Zhang, W. Zong, X. Zhao, L. Wang, R. Wu and X. Hao, Sci. Total Environ., 2009, 407, 4181-4188.

19 A. Vulpoi, V. Simon, H. Ylänen and S. Simon, J. Compos. Mater., 2014, 48, 63-70.

20 A. Balamurugan, G. Balossier, D. Laurent-Maquin, S. Pina, A. H. Rebelo, J. Faure and J. M. Ferreira, Dent. Mater., 2008, 24, 1343-1351.

21 S. P. Valappil, M. Coombes, L. Wright, G. J. Owens, R. J. M. Lynch, C. K. Hope and S. M. Higham, Acta Biomater., 2012, 8, 1957-1965.

22 R. K. Kunkalekar, M. S. Prabhu, M. M. Naik and A. V. Salker, Colloids Surf.,B, 2013, 113, 429-434.

23 A. Vulpoi, C. Gruian, E. Vanea, L. Baia, S. Simon, H. J. Steinhoff, G. Goller and V. Simon, J. Biomed. Mater. Res., Part A, 2012, 100, 1179-1186.

24 C. Gruian, A. Vulpoi, E. Vanea, B. Oprea, H. J. Steinhoff and S. Simon, J. Phys. Chem. B, 2013, 117, 16558-16564.

25 A. Krajewski, R. Malavolti and A. Piancastelli, Biomaterials, 1996, 17, 53-60.

26 D. C. Carter and J. X. Ho, Adv. Protein Chem., 1994, 45, 153203.

27 L. Tang and J. W. Eaton, Am. J. Clin. Pathol., 1995, 103, 466471.

28 M. S. Bahniuk, H. Pirayesh, H. D. Singh, J. A. Nychka and L. D. Unsworth, Biointerphases, 2012, 7, 41.

29 K. Jacobsen, W. L. Hubbell, O. P. Ernst and T. Risse, Angew. Chem., 2006, 45, 3874-3877.

30 C. Gruian, A. Vulpoi, H. J. Steinhoff and S. Simon, J. Mol. Struct., 2012, 1015, 20-26.

31 E. Vanea, C. Gruian, C. Rickert, H. J. Steinhoff and V. Simon, Biomacromolecules, 2013, 14, 2582-2592.

32 T. Peters Jr, All About Albumin: Biochemistry, Genetics and Medical Applications, Academic Press, San Diego, 1st edn., 1995.

33 M. T. Stankovich and A. J. Bard, J. Electroanal. Chem. Interfacial Electrochem., 1978, 86, 189-199.

34 J. L. Hutter and J. Bechhoefer, Rev. Sci. Instrum., 1993, 64, 1868. 
35 J. Lu, J. Bravosuarez, A. Takahashi, M. Haruta and S. Oyama, J. Catal., 2005, 232, 85-95.

36 L. Baia, D. Muresan, M. Baia, J. Popp and S. Simon, Vib. Spectrosc., 2007, 43, 313-318.

37 O. Akhavan, M. Abdolahad, Y. Abdi and S. Mohajerzadeh, J. Mater. Chem., 2011, 21, 387-393.

38 T. Radu, D. Benea, R. Ciceo-Lucacel, L. Barbu-Tudoran and S. Simon, J. Phys. Chem. C, 2012, 116(33), 17975-17979.

39 R. Ciceo Lucacel, O. Ponta and V. Simon, J. Non-Cryst. Solids, 2012, 358, 2803-2809.

40 Y. M. Moustafa and K. El-Egili, J. Non-Cryst. Solids, 1998, 240, 144-153.

41 K. El-Egili, H. Doweidar, Y. M. Moustafa and I. Abbas, Phys. $B, 2003,339,237-245$.
42 A. Barth, Biochim. Biophys. Acta, Gen. Subj., 2007, 1767, 10731101.

43 M. Oblak, A. Prezelj, S. Pecar and T. Solmajer, J. Biosci., 2004, 59, 880-886.

44 A. V. Novikov, R. A. Bublyaev, N. V. Krasnov, Y. P. Kozmin and O. A. Mirgorodskaya, Protein Pept. Lett., 2010, 17, 1392-1397.

45 S. Nafisi, G. Bagheri Sadeghi and A. PanahYab, J. Photochem. Photobiol., B, 2011, 105, 198-202.

46 S. Y. Lin, Y. S. Wei, T. F. Hsieh and M. J. Li, Biopolymers, 2004, 75, 393-402.

47 N. Seidel, J. Sitterberg, W. Vornholt, U. Bakowsky, M. Keusgen and T. Kissel, Biomaterials, 2012, 33, 1929-1938. 48 M. Holmberg and X. Hou, Colloids Surf., B, 2011, 84, 71-75. 